\title{
How many theta roles in a reflexive verb?*
}

\author{
Alexis Dimitriadis \\ Utrecht University \\ a.dimitriadis@uu.nl
}

Martin Everaert

Utrecht University, Institute for Dutch Lexicology

m.b.h.everaert@uu.nl

\begin{abstract}
While purely syntactic approaches to reflexivization have characterized reflexive verbs in terms of detransitivization, we show that there is a discrepancy between syntactic and semantic arity. Reflexive verbs are syntactically intransitive, but semantically they are two-place predicates: both semantic roles of the base verb are syntactically encoded and accessible. We show that detransitivizing reflexivization must involve the assignment of both roles to the same individual, along the lines of the argument-structure operation of bundling (Reinhart \& Siloni 2005), which combines two semantic roles into a single complex role. This allows the bundled roles to be assigned to a single syntactic argument, without special syntactic measures and without violating the theta criterion. We will give empirical support for this analysis by recalling evidence that reflexive verbs are intransitive, and by demonstrating that both theta roles are present in reflexive predicates and are syntactically accessible.
\end{abstract}

Keywords: verbal reflexive; theta roles; Theta System; event semantics

\section{1. "Reflexive anaphors" and "reflexive verbs"}

A simple reflexive predicate as in (1) can be described as involving a single participant (entity in the real world) that is related to an event in two different capacities, often described as thematic roles:

(1) John criticized himself.

Here John is 'the one who criticizes' and 'the one who is being criticized'.

\footnotetext{
* This research was carried out under the auspices of the project Universals and the Typology of Reflexives, funded by the Netherlands Organization for Scientific Research (NWO). We thank Eric Reuland, Dagmar Schadler, Anna Volkova and two anonymous reviewers for their feedback. Hungarian data are drawn from the Anaphora Typology database, and were provided by Judit Gervain. Other data were collected by the authors when no source is cited.
} 
While some reflexive predicates are syntactically transitive, as in (1), others are known to be syntactically intransitive, i.e., they have a single syntactic argument. Our topic is this discrepancy between syntactic and semantic valency, the relationship between the two thematic roles and the single syntactic argument of such reflexives.

As is well-known, reflexivity can be expressed via an argument (a "reflexive anaphor"), cf. (2a)-(5a), or on the predicate, in terms of a "reflexive verb" (or "reflexive-marked verb"), cf. (2b)-(5b). ${ }^{1}$

(2) a. János lát-ta mag-á-t.

(Hungarian)

John.NOM see-PST.3SG.DEF [SELF-POSS.3SG-ACC $]_{\text {REFL }}$

'John saw himself.'

b. János fésül-köd-ik.

John.NOM comb-REFL-PRS.3SG

'John combs his hair (lit. himself).'

(3) a. O Nikos thavmazi ton eafto tu.

(Greek)

the Nick admire.3SG [the SELF his $]_{\mathrm{REFL}}$

'Nick admires himself.'

b. O Nikos ksiriz-ete.

the Nick shave-REFL.3SG

'Nick shaves himself.'

(4) a. Jan bewondert zich-zelf.

(Dutch)

John admires [SE-SELF $]_{\text {REFL }}$

'John admires himself.'

b. Jan scheert zich.

John shaves $[\mathrm{SE}]_{\mathrm{REFL}}$

'John shaves himself.'

(5) a. John admires him-self.

(English)

$[\text { him-SELF }]_{\text {REFL }}$

b. John shaves.

shave.REFL

${ }^{1}$ We use SE as an abbreviation for a multi-functional third person element that is underspecified for number and gender. In example (4) this element is used as a reflexive, or as part of one, while in other examples it is a middle marker (cf. (7), below, from German). When such elements are used with reflexive meaning and there is no danger of confusion, we will simply gloss them as REFL. 
Our focus is on the verbal reflexive constructions, which yield reflexive verbs that we will show to be intransitive. In contrast, in constructions involving argument reflexives, the anaphors himself, magát and ton eafto $t u$ are objects of transitive predicates. Neither the issues nor the solution we propose apply to argument reflexives.

In this paper we will develop the following argument:

1. Reflexive verbs are syntactically intransitive, while their semantics is crucially dependent on two semantic roles, which means that they are dyadic predicates. ${ }^{2}$

2. This discrepancy can be explained by making use (for verbal reflexives only) of the notion of (theta) bundling (Reinhart \& Siloni 2005; Dimitriadis 2004), the combination of two semantic roles into a single complex role. This allows the bundled roles to be assigned to a single syntactic argument.

3. We will give empirical support for bundling by demonstrating that both theta roles are present in reflexive verbs.

In the next subsection we will discuss our definition of what a reflexive is, and subsection 1.2 explains why bundling is needed. Section 2 will show that reflexive predicates are intransitive. In section 3 we explain how the syntax is matched to the semantics, in other words how bundling works. In section 4 we will give evidence that the single NP of these reflexive predicates has both agent and patient properties, which proves the need for the bundling approach of section 3. Section 5 is a short conclusion.

\subsection{What's a reflexive?}

Our notion "reflexive" is based on Faltz (1977), who defines it in terms of an "archetypal reflexive context", as follows:

\footnotetext{
"I assume that, given any language, we can isolate a class of simple [transitive] clauses expressing a two-argument predication, the arguments being a human agent or experiencer on the one hand and a patient on the other. [...]

${ }^{2}$ In the remainder we focus on dyadic verbs in which the first argument is agentive. As a reviewer pointed out, the external argument of a reflexive verb does not have to be an Agent: it could also be an Experiencer (which in the Theta System would be marked as external in the absence of an Agent), and there are (lexical) reflexive verbs cross-linguistically that have an Experiencer subject.
} 
If the language has a grammatical device which specifically indicates that the agent/experiencer and the patient in such clauses are in fact the same referent, then that grammatical device will be called the primary reflexive strategy of that language."

$\left(\right.$ Faltz 1977, 3) ${ }^{3}$

This means that a reflexive is a construction, a grammaticized device. ${ }^{4}$ Note that a transitive base is necessarily involved (though the resulting reflexive predicate may be either transitive or intransitive). Crucially, this definition allows a language to have more than one reflexive device, or none. We distinguish between himself in (5a) and the "zero" reflexive (5b) in English, for example.

From this perspective, only constructions that involve identification of two argument positions can be called reflexives. Other uses of the same grammatical form, such as intensifiers (6), middles (7), or so-called "inherent reflexives" (8), which have no reflexive meaning or a transitive version, are not considered reflexives:

(6) a. The cook caught the fish himself.

b. The cook himself caught the fish.

c. The cook caught the fish by himself.

(7) Dieses Buch liest sich leicht.

(German)

this book.NOM reads SE easily

'This book reads easily.'

(8) Jan vergist zich.

John errs SE

'John is making a mistake.'

\subsection{Why bundling?}

As mentioned above, reflexives involve two semantic roles (theta roles), which are ultimately assigned to the same individual in a reflexive. ${ }^{5}$ While

${ }^{3}$ In addition to distinguishing argument reflexives from verbal reflexives, Faltz classifies reflexives on the basis of their distribution: primary reflexive (a productive reflexive strategy that can be used with any semantically compatible transitive verb), middle reflexive (a strategy restricted to a lexically determined class of verbs), secondary reflexive (used with oblique NPs), etc. These categories do not play a role in our discussion.

${ }^{4}$ See also Dimitriadis \& Everaert (2004).

${ }^{5}$ We know that there are two theta roles because they are assigned to different arguments by the transitive verb underlying the reflexive. 
this can be achieved by coindexing two syntactic arguments (an anaphor and its antecedent), we will show that verbal reflexives like (2b)-(5b) are intransitive: They project only one syntactic argument. In other words, this kind of reflexivization must involve detransitivization of a transitive verb. If so, what happens to the other argument, and what happens to its theta role?

From a syntactic perspective one can say simply that one argument is reduced (dropped). But which argument? If the external argument of a reflexive verb is dropped, the result will be an unaccusative verb. If an internal argument is dropped, it will be an unergative verb.

From a semantic perspective it is important to observe that a compositional approach to semantics forces us to accept that both theta roles continue to be part of the verb meaning, even after detransitivization. Therefore, both must be be assigned to the remaining argument. It is technically very easy to associate two theta roles with the same argument (although this is prohibited by some versions of the theta criterion). Following Reinhart \& Siloni (2005), we call this bundling, and will discuss it in section 3.2 .

The term bundling was introduced in the context of the Theta System (Reinhart 1996; 2000; 2002; Everaert et al. 2012). While our argument depends only on general principles of syntactic arity and thematic roles, we formulate it in terms of the Theta System for concreteness. To avoid misunderstandings, we give a brief overview here.

The Theta System, taken as the central module of the mental system of concepts, consists of lexical entries with features defining the theta relations of verb-entries, and marking procedures which prepare verbal (and other) entries for the syntactic derivation. The system also utilizes a set of lexical arity (valence changing) operations, and covers a plethora of phenomena.

The theory of the Theta System should be clearly distinguished from theta theory as used in the context of government and binding (Chomsky 1981), and also from approaches that give a lexical semantic representation (LSR) an important place in a theory of argument structure. In the Theta System, syntax only has access to argument structure as a projection of a lexicon allowing arity manipulation. Theta roles are place holders for what one could call semantic roles (with labels such as Experiencer, Theme, etc.) at the level of verbal concepts. In this sense the Theta System is like the traditional GB-type theta theory, but it should be borne in mind that the Theta System also diverges from traditional theta theory. Even though we use terms like Theme and Patient in this paper, semantic roles as 
primitives play no role in the Theta System, which in this sense adheres to the criticism formulated in Dowty (1991). But contrary to the position taken by Dowty, the assumption is that the lexical semantics relevant for syntactic derivations can still be formulated in terms of theta roles. But theta roles are defined on the basis of a restrictive lexical semantics, and are composed of the features Cause and Mental State (which can take a plus or minus value or be absent, i.e., unspecified). For the point we want to make in this paper we don't need to agree, or disagree, on whether we need more in terms of a decompositional lexical semantics as sketched in Dowty (1979); Jackendoff (1990); Parsons (1990) or Levin \& Rappaport Hovav (1995). The Theta System is an attempt to formulate a restrictive theory of which aspects of the verbal lexical semantics play a role in the lexicon, the place where argument manipulation is accounted for, and where projection is taken care of. ${ }^{6}$

Before we discuss bundling in more detail, we consider the syntactic side of detransitivization. We must refute the following alternative analysis: Might verbal reflexives (in English and in other languages that concern us) involve a zero object interpreted just like himself? In other words, could John washes have the structure in (9b), fully parallel to (9a)?

(9) a. $\operatorname{John}_{i}$ admires himself ${ }_{i}$.

$$
[\text { him-SELF }]_{\text {REFL }}
$$

b. $\mathrm{John}_{i}$ washes $\phi_{i}$.

REFL

\section{Are reflexive predicates intransitive?}

\subsection{The syntactic structure of se-reflexives}

Several authors have argued for the detransitivizing character of various verbal reflexives, a.o. Grimshaw (1982); Wehrli (1986), and Alsina (1996). Arguments are mostly based on French and Italian, as originally described by Kayne (1975) and Burzio (1981), respectively.

In French, if the complement of a faire-causative is a transitive predicate, its subject must be governed by the preposition $\grave{a}$. This is shown in example (10a). As (10b) shows, the subject of intransitive complements is

\footnotetext{
${ }^{6}$ Whether this restrictive theory is empirically adequate, in comparison to alternatives (Horvath \& Siloni 2011; 2013; Beavers \& Koontz-Garboden 2013a;b), is an important question but not one that we address in this paper.
} 
expressed without the preposition. Se-reflexive constructions (10c) behave on a par with intransitives, and contrast with transitives:

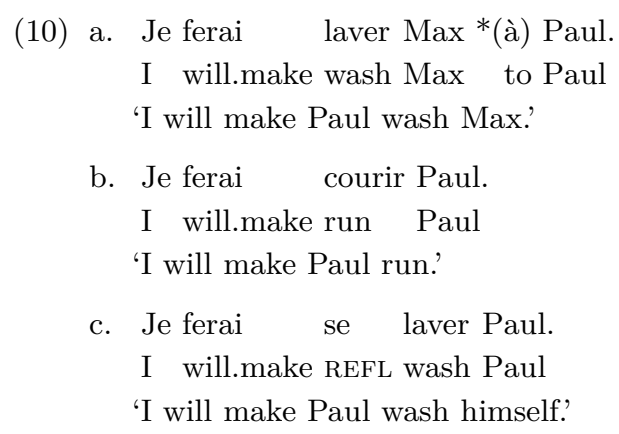

This conclusion is consistent with the fact that se, unlike pronominal (nonreflexive) object clitics, can attach to a verb embedded under faire:

(11) a. *La crainte du scandale l'a fait la tuer.

the fear of scandal him-has made her kill

'The fear of scandal made him kill her.'

b. La crainte du scandale l'a fait se tuer.

the fear of scandal him-has made SE kill.

'The fear of scandal made him kill himself.'

The conclusion seems to be that these reflexive verbs are syntactically intransitive. $^{7}$

\subsection{The syntactic structure of the English "zero" reflexive}

Given what we have seen in French and Italian, we now consider whether English reflexive verbs like the one in (5b), repeated here for convenience, are also intransitive.

(5) a. John admires him-self.

$[\text { him-SELF }]_{\text {REFL }}$

b. John shaves.

shave.REFL

\footnotetext{
${ }^{7}$ We leave aside whether they are unaccusative or unergative, since for our purposes it is sufficient to show intransitivity.
} 
To find this out we use the object comparison test of Zec (1986), who used it to show that the clitic se in Serbian is not an argument of the verb but a verbal operator. The test has wide cross-linguistic applicability, and rests on the object comparison reading of the comparative ellipsis construction $(12): 8$

(12) John hates Bill more than George.

a. Subject comparison (irrelevant to transitivity) John hates Bill more than George Bill.

b. Object comparison

John hates Bill more than George.

While the interpretation of subject comparison involves VP-ellpisis, the object comparison reading requires us to substitute George for the object of the ellipsis antecedent, John hates Bill. Object comparison, in other words, requires a transitive antecedent clause, and can hence be used as a robust test of transitivity. If we now use a reflexive clause as the antecedent for the comparative ellipsis, we find the following:

(13) John washes himself more than George.

a. Subject comparison, strict or sloppy John washes himself more than George John/himself.

b. Object comparison John washes himself more than George.

(14) John washes more than George.

a. Subject comparison John washes himself more than George hashes himself.

b. Object comparison

*John washes himself more than George.

The object comparison reading in (13) confirms that John washes himself is transitive. Example (14) disallows the object comparison reading, showing that John washes is intransitive. (We have provided subject comparison readings for completeness, but they play no role in this argument.) We conclude that wash-type reflexives in English are syntactically intransitive rather than, say, having a zero object as suggested in (9b). Applying the test to French se-reflexives gives the same result.

${ }^{8}$ When applying this test to languages with morphological case, accusative case on George can force unambiguous object comparison. 


\subsection{Not quite a minimal pair: reflexive sich (German) and zich (Dutch)}

The evidence for German is somewhat mixed, but several tests suggest that sich 'himself/herself' is an argument. That would mean that sichreflexives are transitive. Example (15) shows that sich allows an object comparison reading, indicating that (15) is transitive:

(15) Die Pferden hassen sich mehr als den Hund.

the horses hate REFL/RCP more than the.ACC dog

$=$ The horses hate REFL/RCP more than herses the dog.

'The horses hate themselves/each other more than (they hate) the dog.'

Another test indicating that sich-reflexives are transitives, is the focus test discussed by Schäfer (2013). The focus element selber in a sentence like (16) can be interpreted with respect to the subject (agent) or to the object (patient), indicating that both are syntactically present and accessible to focus:

(16) Morgens wäscht sie sich immer/erst mal selber.

at.morning washes she REFL always/first-of-all SELF

a. agent focus

She washes herself, no-one else washes her. (context: She is a disabled patient.)

b. patient focus

She washes herself, she washes no-one else. (context: She is a nurse.)

The fact that patient focus is possible shows that sich really is the object, and these sentences are transitive. For Dutch, on the other hand, the corresponding examples are ungrammatical. It can be seen from (17) that zichzelf 'himself' allows an object comparison reading, but zich does not:

\section{(17) Object comparison}

a. Peter verwondt zichzelf vaker dan haar.

Peter injures REFL more.often than her.ACC

$=$ Peter injures REFL more.often than her.

'Peter injures himself more often than he injures her.'

b. *Peter wast zich vaker dan haar.

Peter washes REFL more.often than her.ACC

= Peter washes REFL more.often than her.

'Peter washes himself more often than he washes her.'

Likewise, the focus test indicates that agent focus is possible but patient focus is not: 
(18) In de ochtend wast hij zich eerst zelf in the morning washes he REFL first SELF

a. agent focus

$=$ He washes himself, no-one else washes him.

b. *patient focus

$=$ He washes himself, he washes no-one else.

We conclude that Dutch zich-reflexives are syntactically intransitive.

\section{Matching the syntax to the semantics}

Having demonstrated that reflexive verbs (in some languages) are intransitive, we now consider the question of what kind of intransitives they are. From the syntactic perspective, the question that has been extensively studied is whether the remaining argument of reflexives is projected as an internal or external argument of the verb, i.e., whether reflexive verbs are unaccusative or unergative. (Note that from our perspective, this question is not particularly important; what matters is that there is one syntactic argument, not two.)

Much of the literature adopts the view that reflexives are unaccusatives: the clitic absorbs the external argument (Marantz 1984; Bouchard 1984; Grimshaw 1990), or is itself the external argument (Kayne 1988; Pesetsky 1995; Sportiche 1988). However, it has also been argued that reflexive verbs are unergatives, formed through the elimination of the internal theta role (Chierchia 2004; Reinhart 1996; 2000; Reinhart \& Siloni 2004). Specifically, Chierchia and then Reinhart define the argument structure of reduction, which Reinhart and Siloni (2004) describe as follows:

(19) "Reduction applies to a two-place relation (predicate), identifies the two arguments, and reduces the relation to a property. Reflexive reduction turns a transitive entry such as wash into an intransitive entry whose single $\theta$-role is the external $\theta$-role."

(Reinhart \& Siloni 2004)

We will remain agnostic on the question of internal or external projection, since nothing in our analysis depends on it. We now turn to the meaning of a reflexive sentence like (20). This should be essentially the same as for a non-reflexive sentence involving wash, which has both an agent and a patient. In other words, Jean is both the agent and the patient of washing in $(20)$. 
(20) Jean se lave.

John REFL washes

'John washes.'

\subsection{Resolving the mismatch}

To discuss verb meaning, we adopt an event semantics (Parsons 1990; Landman 2000), which allows theta roles to be explicitly represented. Sentence (20) is assigned the semantics in (21a). Reduction, in the sense of Reinhart \& Siloni (2004), would completely eliminate the internal theta role, leaving the "identified" arguments with only the external role as shown in (21b). Semantically, this is incorrect.

(21) a. $\exists e \operatorname{wash}(e) \wedge \operatorname{Agent}(e$, Jean $) \wedge \operatorname{Patient}(e$, Jean $)$

b. $\exists e \operatorname{wash}(e) \wedge \operatorname{Agent}(e$, Jean $)$

The syntax of reflexive verbs, then, suggests that they should have just one thematic role, while the correct semantics involves two. To resolve this mismatch, we have several options:

a. One might, contrary to our intuition and the general consensus, consider theta roles to be purely syntactic objects. According to this view they are revelant to argument projection, and have nothing to do with actual verb meaning. If so, reflexive verbs would simply have the single theta role that their syntax justifies.

b. To avoid giving up the intuition that thematic roles represent a real part of verb semantics, we might introduce separate notions of theta roles for the syntax and the semantics. We could then assert that there is only one syntactic theta role, but the verb retains both semantic ones. While it seems to promise a satisfactory account of reflexive verbs in both domains, this position would require us to provide a theory of the correspondence of syntactic and semantic theta roles, and to specify how each arity-manipulating operation affects syntactic and semantic theta roles. Although attempts have been made to flesh out a theory of theta roles along such lines (cf. Jackendoff 1990), we will show that this position is in any event incorrect. ${ }^{9}$

${ }^{9}$ Note that it would make no difference, except in our formulation, if we abandoned the idea of theta roles as distinct entities altogether and considered only the associated entailments (cf. Dowty 1989; 1991; Beavers \& Koontz-Garboden 2013a;b). The question would simply become what happens to the entailments associated 
c. Instead of deleting the second theta role, we can assign them both to the single remaining syntactic argument. While this goes against some formulations of the theta criterion (but not others), we will show that it is the most empirically successful approach.

In section 4 we will show that both thematic roles are still syntactically relevant in reflexive verbs, ruling out options (a) and (b) and leaving us with option (c): assigning both roles to the same NP. This is expressed in a straightforward way through the operation of "bundling," to which we now turn.

\subsection{Bundling: identifying two theta roles}

The naive way of associating both theta roles of the reflexive predicate with the remaining argument, as suggested by approach (c) above, would violate the theta criterion (Chomsky 1981):

(22) Theta Criterion (Chomsky 1981, 36)

Each argument bears one and only one $\theta$-role, and each $\theta$-role is assigned to one and only one argument.

The theta criterion has been dramatically revised and weakened in the intervening years (cf. Marelj 2004, 44-55 for discussion), but in any case the problem is technically easy to bypass in the context of reflexivization, since both theta roles reside in the same lexical verb. Bundling (Reinhart \& Siloni 2005; Dimitriadis 2004; 2012) is an arity operation that combines two theta roles into a single, complex one. Reinhart \& Siloni (2005), who adopted bundling in place of reduction as the arity operation behind reflexivization, summarize it as follows:

(23) Reflexivization Bundling (Reinhart \& Siloni 2005)

$\left[\theta_{i}\right]\left[\theta_{j}\right] \rightarrow\left[\theta_{i}-\theta_{j}\right]$

Restriction: $\theta_{i}$ is an external $\theta$-role.

Semantically, a two-place (transitive) predicate has an event semantics denotation like (24a). It can easily be transformed into the one-place pred-

with the two arguments of the transitive verb; either both sets are linked to the single syntactic argument of the reflexive verb, or they are not. (The mechanisms for doing so would presumably change, however, according to the particular theory one adopts.) 
icate in (b), ${ }^{10}$ which assigns both Agent and Patient roles to its single argument.

(24) Semantic counterpart (Dimitriadis 2004)

a. wash: $\quad \lambda x \lambda y \lambda e \operatorname{wash}(e) \& \operatorname{Agent}(e, y) \& \operatorname{Patient}(e, x) \quad$ (transitive)

b. wash $_{\mathrm{refl}}: \lambda x \lambda e \operatorname{wash}(e) \& \operatorname{Agent}(e, x) \& \operatorname{Patient}(e, x) \quad$ (reflexive)

Bundling, then, is a simple way to assign two theta roles to a single NP. This can be said to avoid a violation of the theta criterion, since the argument of the reflexive does not receive a theta role twice but is assigned a (complex) theta role only once, through the same process of verb-argument association that would assign one unbundled theta role to an argument. Adherents of a strict conceptualization of the theta criterion might oppose this solution, taking the view that the "bundled" theta role remains two separate roles. But the constituent structure of the bundled role is only apparent in the semantics, while the theta criterion is a syntactic constraint - semantics imposes no restriction against saturating two logical predicates (including theta roles) with instances of the same variable.

In any case we are not opposed to an even weaker version of the theta criterion, which requires arguments to receive a theta role but does not enforce biuniqueness (Culicover \& Wilkins 1984). ${ }^{11}$ Readers who are not worried about the theta criterion may ignore the above discussion, and observe simply that bundling implements the idea that both theta roles remain present in the verb, rather than one of them being demoted as in reduction-based analyses.

In the following section, we will demonstrate that we do indeed need to retain and assign both theta roles. In the verbal reflexives that we have considered they are syntactically active, i.e., accessible to syntax, just as the agent is present in passives.

10 The operation that carries this out can be written in general form as follows (Dimitriadis 2004):

(i) $\operatorname{REFL}=\lambda P_{\langle e,\langle e, s t\rangle\rangle}[\lambda x \lambda e P(x)(x)(e)]$

This takes a two-place predicate $P$, and embeds it in a one-place predicate whose single argument is used to saturate both open arguments of $P$.

11 As has been pointed out by several authors, even in Chomsky (1981) the biuniqueness constraint was relaxed. We quote from (Marelj 2004, 44): "in fn. 14, p. 139 he makes it clear that the prime objective of the Theta Criterion is not to prevent arguments from getting more than one theta-role, but to prevent them from getting more than one theta-role in the course of the derivation". See also Chomsky (1986) 


\section{Testing for agents and patients}

We now test for the presence of syntactically accessible agents and themes/ patients, irrespective of their syntactic position. ${ }^{12}$ Note that it is not enough for an event to be conceptually compatible with particular thematic roles (which we might call being semantically present). To establish that reflexivization does not remove a thematic role, we must show that it remains syntactically accessible in some suitable, non-trivial sense. Consider the well-known case of the suppressed agent of passives (Roeper 1987). An event of sinking is logically compatible with an agentive causer, but the unaccusative sentence (25a) does not include a linguistically present agent and is therefore incompatible with a purpose infinitive. The passive variant (25b), on the other hand, licences a purpose infinitive even though the agent is not overtly realized; we say that the thematic role Agent is still accessible to modifiers that select for it (hence "active" in a relevant sense), whatever that might involve in the particulars of the theory adopted.

(25) a. The boat sank to collect the insurance.

b. The boat was sunk to collect the insurance.

Note also that the need for a syntactically accessible agent is a particular property of the purpose infinitive. Other constructions can freely refer to an unexpressed agent, or to intentional action that is pragmatically accommodated:

(26) a. The boat sank because someone wanted to collect the insurance.

$$
\text { (= someone sank it) }
$$

b. Bill died because he wouldn't keep his mouth shut. (= somebody killed him)

Another example, closer to the issue under discussion, is given by Rizzi (1986):

12 Since the particular theta roles involved are of no consequence to our analysis, we adopt the broad definition that uses Theme and Patient interchangeably.

Testing for specific theta roles is not very common in the literature. Many linguists assume or assert that syntactic rules cannot make direct reference to specific thematic roles, the effects of a theta role being limited to determining the syntactic projection occupied by the argument that receives it. However, Maling (2001) argues that theta roles and syntactic positions can be independently tested for, and shows that certain syntactic rules target themes rather than goals. (Her tests, drawn from Baker 1997, do not distinguish between agent and theme/patient, and unfortunately we have been unable to utilize them for our purposes.) 
(27) a. Questa decisione rende tutti felici.

(Italian)

this decision makes all happy

'This decision makes everyone happy.'

b. Questa decisione rende felici.

this decision makes pro happy

'This decision makes one happy.'

(28) a. This decision makes everyone happy

(English)

b. *This decision makes happy

(intended: For all $x$, this decision makes [x happy].)

Rizzi observes that in Italian, both the overt arbitrary third person human interpretation and the non-overt prototypical-object interpretation, where the verb's lexical semantics identifies the object, are available (cf. $(27 a, b))$. But in English only the overt variant is available (cf. (28)). Rizzi argues that non-overt in Italian means the presence of an arbitrary small pro, that is an object that is syntactically overt, while in English the direct object is, in fact, absent, making the verb syntactically intransitive. However, note that in both Italian and English the verb will be specified for an object theme/patient. In English this lexical semantic feature, whether viewed as a thematic role or a lexical entailment, is syntactically not accessible, leading to the ungrammaticality of (28b).

We will demonstrate the same kind of syntactic accessibility for both thematic roles of reflexive verbs, focusing on Agent-Patient verbs because they are the simplest. We assume that our conclusions apply to transitive verbs with other combinations of theta roles, but we must leave open the question of how to test for them.

\subsection{Reflexives are agentive}

While it is not really in dispute that reflexive verbs are agentive (if the transitive base verb was agentive), we will provide evidence to demonstrate that it is indeed so: Reflexive verbs can be used with agent-oriented adverbs, with imperatives, and in the complement of the verb persuade. These diagnostics were first used by Lakoff (1966) as tests of the stativeeventive distinction; Levin (2007) points out that they are really tests of agentivity. We illustrate with the reflexive verb shave:

(29) a. John shaved carefully.

b. Shave!

c. Mary persuaded John to shave. 
The adverb carefully targets agents, not subjects, as we can see by its compatibility with the agentive (30a) but not the non-agentive $(30 \mathrm{~b}, \mathrm{c}){ }^{13}$ While the agent need not be overtly realized, it must be syntactically accessible in the same sense discussed in the previous section: carefully is licensed by the passive (30a), whose demoted agent is not overtly present, but not by the corresponding unaccusative (30b) which, it is generally understood, completely lacks an agent (Roeper 1987; see also section 4 above).

(30) a. John threw the rock carefully.

b. ${ }^{2 *}$ John died carefully.

c. *John carefully fears the snake.

(31) a. The boat was carefully sunk.

b. ${ }^{*}$ The boat sank carefully.

This is therefore a good test for syntactically accessible agents in English, regardless of their syntactic position (if any). Similarly, it can be shown that only agentive verbs can be used as (non-negated) imperatives, or serve as the complement of persuade, promise, etc. As we have seen in example (29), reflexive verbs in English pass these agentivity tests.

In Dutch, we can again use the agent-oriented adverb opzettelijk 'intentionally'. To see that it requires an agent, note that it is compatible with active or passive agents as in $(32 \mathrm{a}, \mathrm{b})$ but not with non-agentive examples such as $(32 \mathrm{c}, \mathrm{d})$. Example (32e) shows that opzettelijk is indeed compatible with the reflexive verb zich wassen 'to wash oneself', proving that the latter is agentive.

(32) a. Jan gooide de kei opzettelijk.

John threw the rock intentionally

${ }^{13}$ A reviewer points out that the same tests also give a positive result in the following cases from the BNC:

(i) He was carefully tactful about his appearance in the ship's operational areas.

(ii) She was careful reticent on such occasions.

(iii) Be tactful!

(iv) Mary persuaded John to be tactful.

These examples might indicate that the adjective tactful has a syntactically active Agent. We accept this point, and observe that the concept of agentive adjectives has been defended (Geuder 2002). Note that the above examples are about behaving tactfully on a particular occasion, and behavior is indeed attributable to an Agent. We could say that it is not tactful but be tactful that has a syntactically active agent. 
b. De kei werd opzettelijk gegooid. the rock was intentionally thrown

c. ${ }^{*}$ De kei zonk opzettelijk. the rock sank intentionally

d. ${ }^{*}$ Jan stierf opzettelijk. ${ }^{14}$ John died intentionally

e. Jan wast zich opzettelijk (slecht). John washes REFL intentionally poorly

'John washes himself (poorly) intentionally.'

\subsection{Testing for patient}

We now test for the presence of a second syntactically accessible theta role in reflexive verbs. We will show that reflexives are compatible with adverbs that require a syntactically realized theme. ${ }^{15}$ To demonstrate this successfully, we must show that themes, rather than internal arguments, are needed to license our adverbs.

Note first that the adverb completely requires a syntactically accessible theme. It is not compatible with object drop (with verbs that allow it), even though we could easily imagine an interpretation for such sentences. ${ }^{16}$

(33) a. John sang (the song). c. John sang the song completely.

b. John baked (the cake). d. *John sang/baked completely.

14 The Dutch verb sterven is unaccusative, as shown by the following generally accepted diagnostics. We acknowledge that none of them are entirely straightforward in their interpretation (cf. Ackema 1999 for discussion), since there is no a priori reason for them to be associated with unaccusativity.

(i) Auxiliary selection: It selects a be auxiliary, like other unaccusatives

(ii) It cannot form an impersonal passive.

(iii) It allows attributive past participles.

15 As mentioned above, we adopt a broad definition of Theme that does not distinguish it from Patient.

${ }^{16}$ Note that while our tests of agentivity accept the covert agent of passives, the unexpressed object of a verb like bake is not accessible to the adverb completely. We cannot say whether this is due to differences in the tests we have chosen (e.g., perhaps our theme-oriented adverbs require an overtly expressed licenser), or an indication that demoted subjects and unexpressed objects are of fundamentally different nature. Since the arguments of reflexives satisfy both groups of tests, it is not necessary for us to take a position on this question. 
The above show that the adverb completely is only acceptable when the theme is in object position. To show that a theme, rather than an internal argument, is required to license it (i.e., that this licensing condition is thematic rather than structural), consider the derived subjects in (34a,b), in which the theme is generated internally and raised to subject, and most crucially example (34c), a "theme unergative" (cf. Levin \& Rappaport Hovav 1995) whose theme subject is base-generated externally and hence has no object in any stage of its derivation.

(34) a. The fruit was peeled completely.

[passive theme]

b. The vase broke apart completely.

[unaccusative]

c. The rose blossomed completely.

[theme unergative]

Naturally, there are other restrictions on the use of completely. The predicate must allow a telic interpretation: The object must be suitably bounded, which rules out indefinite plurals like (35a) ${ }^{17}$ and the meaning of the verb must have a natural endpoint, which makes completely incompatible with some theme unergatives, like the emission verb shine. Other emission verbs like light up work as expected:

(35) a. *John baked cakes completely.

b. *The diamond shone completely.

c. The neon sign lit up completely.

For a second diagnostic, consider the adverb painfully. It similarly requires a syntactically accessible patient/theme under its core meaning, that the event described by the predicate caused pain in the undergoer. It is therefore incompatible with the unexpressed object in (36b), and with the agentive unergative (36c); but it is compatible with the transitive (36a), the unaccusative (36d), and the theme unergative (36e).

(36) a. Mary hit me painfully.

b. *Mary hit painfully. [unexpressed theme]

c. *Bill ran painfully. [unergative]

d. Bill fell painfully. [unaccusative]

e. Everyone began to sweat painfully after a few mouthfuls [of spicy food]. ${ }^{18}$

[theme unergative]

17 We thank an anonymous reviewer for bringing this condition to our attention.

${ }^{18}$ While verbs of emission don't normally describe events that are painful to the undergoer, natural examples do occur in the right context. Example (36e) is 
Unfortunately, while the intuitions underlying the above discussion are robust, the use of painfully is considerably more nuanced than we have indicated. A reviewer pointed out several examples from the British National Corpus (BNC):

(37) a. She swallowed painfully.

b. But it hadn't simply been desire, she acknowledged painfully.

c. Do you really believe that? she whispered painfully.

d. Bath might discover painfully what Winterbotton has in mind.

With the exception of swallow, the above are transitive verbs with a clausal complement, and clearly the pain is felt by the subject (the speaker or discoverer). Note that here the pain does not result from the action, and is emotional or metaphorical rather than (for lack of a better term) actual physical pain. Our American English informants pointed out that such examples are stylistically marked, "like reading literature," and indeed, such examples in the BNC come disproportionately from the romantic and fantasy literature. All five examples of swallowed painfully in the BNC come from this genre, and their protagonist is female (masculine pronouns outnumber feminine ones two to one in the $\mathrm{BNC}$ over all). This one gives the flavor best:

(38) The covering of hair did nothing to disguise the rippling muscles, as he moved to the chair she'd indicated, and she swallowed painfully.

$(\mathrm{BNC})$

Another reviewer points out the following issue, confirmed by our informants: While (36c) is degraded, adding an explicit goal as in (39b) is considerably better. Examples of this sort are particularly intriguing because of the connection with unaccusativity, ${ }^{19}$ but in any event it is clear that what licenses the adverb here is not a simple theme.

(39) a. ${ }^{*}$ Bill ran painfully. $(=(36 \mathrm{c}))$

b. 'Bill ran painfully to the store.

from http://stephenjohndawson.blogspot.nl/2007_10_01_archive.html. Retrieved on $2013 / 3 / 1$.

${ }^{19}$ It is long known that when motion verbs (unergative) are combined with a telic directional PP, they become unaccusative (directed motion verbs). Cf. discussion in Levin \& Rappaport Hovav (1995). 
In view of the above complications, it is clear that the use of the adverb painfully needs further study; until then its usefulness as a diagnostic for English is limited.

Turning now to reflexive verbs, we find that our test adverbs can be freely used with them, demonstrating that reflexive verbs possess a syntactically accessible patient role.

(40) a. John shaved/disrobed completely.

b. Bill shaved, painfully, with a dull razor.

Similarly, examples (41) and (42) show that the Dutch adverb volledig 'completely' requires an accessible theme:

(41) a. Jan zong het lied volledig.

John sang the song completely

b. *Jan zong volledig.

John sang completely

(42) a. Jan liep de marathon volledig.

John ran the marathon completely

b. *Jan liep volledig.

John ran completely

Example (43b) shows that volledig is compatible with reflexives. Hence zich-reflexives in Dutch, like English reflexive verbs, retain their patient theta role.

(43) a. Jan waste het kind volledig.

John washed the child completely

b. Jan wast zich volledig.

John washes REFL completely

'John washes (himself) completely.'

\section{Conclusion}

Although purely syntactic approaches to reflexivization have characterized reflexive verbs in terms of detransitivization, we have shown that there is in fact a discrepancy between syntactic and semantic arity. Reflexive verbs are syntactically intransitive, i.e., they project a single argument. 
Semantically, however, they are two-place predicates: both semantic roles of the base verb are syntactically encoded and accessible.

While the retention of both theta roles at some level is inevitable, given the semantics of reflexives, we have shown that their effects are not limited to interpretation. Both theta roles must be syntactically "accessible" in a sense strong enough to license manner adverbs and other syntactic constructions. There are many imaginable ways to make this precise, and the details depend on the specifics of the syntactic theory adopted; but any analysis must take into account the fact that both theta roles of the predicate are available, and that both are ultimately associated with the same syntactic argument. We have shown that bundling is a straightforward, theoretically well-motivated way to express this relationship, and that it naturally bypasses a potential violation of the theta criterion: the two theta roles of the transitive verb are "bundled" into a single, complex theta role, which can be assigned to an argument in a single operation without violating any constraints.

A somewhat unusual aspect of our approach is the principled focus on the syntactic properties of theta roles as opposed to structural arguments like subject and direct object. This was especially felt in connection with detecting patients, a task for which there are no well-established tests. We have relied on carefully chosen manner adverbs, but hope that more diverse tests can be established.

\section{References}

Ackema, Peter. 1999. Issues in morphosyntax. Amsterdam \& Philadelphia: John Benjamins.

Alexiadou, Artemis, Elena Anagnostopoulou and Martin Everaert (eds.). 2004. The unaccusativity puzzle. Oxford: Oxford University Press.

Alsina, Alex. 1996. The role of argument structure in grammar: Evidence from Romance. Stanford, CA: CSLI.

Baker, Mark. 1997. Thematic roles and syntactic structure. In L. Haegeman (ed.) Elements of grammar. Dordrecht: Kluwer. 73-137.

Beavers, John and Andrew Koontz-Garboden. 2013a. Complications in diagnosing lexical meaning: A rejoinder to Horvath and Siloni (2013). Lingua 134. 210-218.

Beavers, John and Andrew Koontz-Garboden. 2013b. In defense of the reflexivization analysis of anticausativization. Lingua 131. 199-216.

Bouchard, Denis. 1984. On the content of empty categories. Dordrecht: Foris.

Burzio, Luigi. 1981. Intransitive verbs and Italian auxiliaries. Doctoral dissertation. MIT.

Chierchia, Gennaro. 2004. A semantics for unaccusatives and its syntactic consequences. In Alexiadou et al. (2004, 22-59). 
Chomsky, Noam. 1981. Lectures on government and binding. Dordrecht: Foris.

Chomsky, Noam. 1986. Knowledge of language: Its nature, origin and use. New York: Praeger.

Culicover, Peter W. and Wendy K. Wilkins. 1984. Locality in linguistic theory. New York: Academic Press.

Dimitriadis, Alexis. 2004. An event semantics for the Theta System. Ms. Utrecht institute of Linguistics OTS.

Dimitriadis, Alexis. 2012. An event semantics for the Theta System. In Everaert et al. (2012, 308-353).

Dimitriadis, Alexis and Martin Everaert. 2004. Typological perspectives on anaphora. In P. Suihkonen and B. Comrie (eds.) Collection of papers from the International Symposium on Deictic Systems and Quantification in Languages Spoken in Europe and North and Central Asia. Iževsk: Udmurt State University. 51-67.

Dowty, David R. 1979. Word meaning and Montague grammar: The semantics of verbs and times in generative syntax and in Montague's PTQ. Dordrecht: Reidel.

Dowty, David R. 1989. On the semantic content of the notion 'thematic role'. In G. Chierchia, B. H. Partee and R. Turner (eds.) Properties, types and meanings. Vol. II: Semantic issues. Dordrecht: Kluwer. 69-130.

Dowty, David R. 1991. Thematic proto-roles and argument selection. Language 67. 547-619.

Everaert, Martin, Marijana Marelj and Tal Siloni (eds.). 2012. The theta system: Argument structure at the interface. Oxford: Oxford University Press.

Faltz, Leonard M. 1977. Reflexivization: A study in universal syntax. Doctoral dissertation. University of California at Berkeley.

Geuder, Wilhelm. 2002. Oriented adverbs: Issues in the lexical semantics of event adverbs. Doctoral dissertation. Universität Tübingen.

Grimshaw, Jane. 1982. On the lexical representation of Romance reflexive clitics. In J. Bresnan (ed.) The mental representation of grammatical relations. Cambridge, MA: MIT Press. 87-148.

Grimshaw, Jane. 1990. Argument structure (Linguistic Inquiry Monograph 18). Cambridge, MA: MIT Press.

Horvath, Julia and Tal Siloni. 2011. Anticausatives: Against reflexivization. Lingua 121. $2176-2186$.

Horvath, Julia and Tal Siloni. 2013. Anticausatives have no cause(r): A rejoinder to Beavers and Koontz-Garboden. Lingua 131. 217-230.

Jackendoff, Ray. 1990. Semantic structures. Cambridge, MA: MIT Press.

Kayne, Richard S. 1975. French syntax: The transformational cycle. Cambridge, MA: MIT Press.

Kayne, Richard S. 1988. Romance se/si. GLOW Newsletter 20.

Lakoff, George. 1966. Stative adjectives and verbs in English. Report NSF-17, Harvard Computation Lab.

Landman, Fred. 2000. Events and plurality: The Jerusalem lectures. Dordrecht: Kluwer.

Levin, Beth. 2007. The lexical semantics of verbs II: Aspectual approaches to lexical semantic representation. Handout from course taught at the LSA Summer School, Stanford University, July 1-3, 2007.

Acta Linguistica Hungarica 61, 2014 
Levin, Beth and Malka Rappaport Hovav. 1995. Unaccusativity. At the syntax-lexical semantics interface. Cambridge, MA: MIT Press.

Maling, Joan. 2001. Dative: The heterogeneity of the mapping among morphological case, grammatical functions, and thematic roles. Lingua 111. 419-464.

Marantz, Alec. 1984. On the nature of grammatical relations. Cambridge, MA: MIT Press.

Marelj, Marijana. 2004. Middles and argument structure across languages. Doctoral dissertation. Utrecht University.

Parsons, Terence. 1990. Events in the semantics of English: A study in subatomic semantics. Cambridge, MA: MIT Press.

Pesetsky, David. 1995. Zero syntax: Experiencers and cascades. Cambridge, MA: MIT Press.

Reinhart, Tanya. 1996. Syntactic effects of lexical operations: Reflexives and unaccusatives (Uil-OTS Working Papers in Linguistics 97-002). Utrecht: University of Utrecht.

Reinhart, Tanya. 2000. The Theta System: Syntactic realization of verbal concepts (OTS Working Papers in Linguistics). Utrecht: Utrecht Institute of Linguistics OTS.

Reinhart, Tanya. 2002. The Theta System: An overview. Theoretical Linguistics 28. 229-290.

Reinhart, Tanya and Tal Siloni. 2004. Against the unaccusative analysis of reflexives. In Alexiadou et al. (2004, 159-180).

Reinhart, Tanya and Tal Siloni. 2005. The lexicon-syntax parameter: Reflexivization and other arity operations. Linguistic Inquiry 36. 389-436.

Rizzi, Luigi. 1986. Null objects in Italian and the theory of pro. Linguistic Inquiry 17. $501-557$.

Roeper, Thomas. 1987. Implicit arguments and the head-complement relation. Linguistic Inquiry 18. 267-310.

Schäfer, Florian. 2013. Passives of reflexive verbs: The repair of a Principle A violation. In P. Brandt and E. Fuß (eds.) Repairs: The added value of being wrong (Interface Explorations 27). De Gruyter Mouton: Berlin \& New York. 335-360.

Sportiche, Dominique. 1988. A theory of floating quantifiers and its corollaries for constituent structure. Linguistic Inquiry 19. 425-449.

Wehrli, Eric. 1986. On some properties of French clitic se. In H. Borer (ed.) The syntax of pronominal clitics (Syntax and Semantics 19). New York: Academic Pres. 263-283.

Zec, Draga. 1986. Objects in Serbo-Croatian. In D. Feder, M. Niepokuj, V. Nikiforidou and M. van Clay (eds.) Proceedings of the Twelfth Annual Meeting of the Berkeley Linguistics Society. Berkeley, CA: Berkeley Linguistics Society. 358-371. 